\title{
2
}

УДК 159.99

\section{О КОМПОНЕНТАХ ЛИЧНОСТНОЙ ЗРЕЛОСТИ}

\author{
Гудзовская Алла Анатольевна \\ Шпунтова Виктория Владимировна
}

Работа выполнена при финансовой поддержке Российского гуманитарного научного фонда (проект 14-16-63004 a(p))

Статья посвящена решению ряда задач: авторы уточняют понятие «личностная зрелость», анализируют проблемы становления личностной зрелости; экспериментально проверяют предположение о том, что компоненты личностной зрелости (эго-идентичность, активное владение собственным окружением, самореализация) формируются в своей основе в возрасте семи-восьми лет.

В работе представлены результаты лонгитюдного исследования компонентов личностной зрелости. В группу лонгитюда вошли 232 ученика первых классов общеобразовательных школ г. Самары и г. Тольятти. Из них приняли участие во всех срезах логнитюда 96 человек. Первое исследование проведено в 1997-1998 г2., когда испытуемые обучались в первом классе. К моменту последнего исследования (2014-2015 г2.) все испытуемые успешно завершили школьное обучение и получили среднее специальное и/или высшее образование (средний возраст - 24-25 лет).

Для исследования компонентов личностной зрелости применялось сочинение на тему «Я человек», были использованы методика предельных смыслов Д. А. Леонтьева, контент-анализ и метод экспертных оценок.

Было обнаружено, что становление личностной зрелости происходит в процессе решения жизненных задач и построения отношений с миром (обществом): человек осознает себя («Я»); формирует образ человека - носителя социальных ролей («Человек», «Я и Человек»), он осознает свою включенность в культуру и воздействует на себя и других людей через различные формы внешней и внутренней активности, выступает автором внутреннего мира («Я - Человек»). Эмпирически установлено, что компонентами достижения личностной зрелости являются: сформированная эго-идентичность, активное владение собственным окружением - способность вести себя независимо от воздействующих обстоятельств и руководствоваться собственными, сознательно поставленными целями, самореализация. В своей основе они формируются в возрасте 7-8 лет.

Полученные результаты представляют интерес для психологов, 


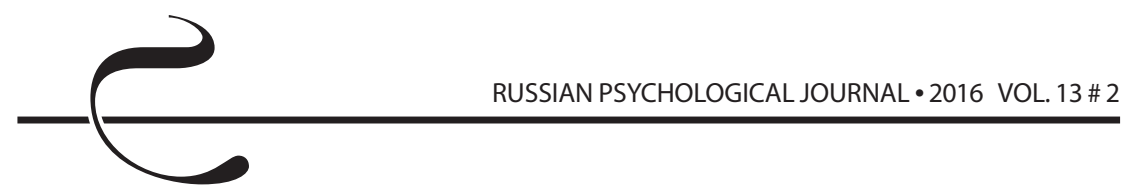

педагогов, сочиальных работников и др. Основные положения работы могут выступить в качестве новых оснований для коррекционно-развивающей работы школьного психолога с челью оптимизачии учебно-воспитательного прочесса.

Ключевые слова: личность, личностная зрелость, сочиальная зрелость, Я и Человек, ценности, личностные смыслы, эго-идентичность, самореализачия, субъектная позичия, авторство личности.

\section{Введение}

Проблема личности - значимая и сложная. Понятие личности - многозначное и многоплановое. Личность не дана человеку наперед, она - относительно поздний продукт развития человеческого общества [7, с. 491]. Личность есть новообразование, свойственное только человеку, - оно формируется в процессе становления культуры. Человек как личность выступает автономным носителем и субъектом общественно выработанных форм отношения к миру; он овладевает собственным поведением в соответствии с принятыми нормами и правилами, регулирует собственную жизнь и выстраивает свое отношение к миру, другим людям.

Для описания полноценного функционирования личности в отечественной психологии используется понятие «личностная зрелость». Согласно К. А. Абульхановой-Славской, зрелость - это способность человека целесообразно расходовать жизненные силы, продуктивно применять свои личностные возможности и особенности: «Зрелый человек способен своей волей определять и направлять ход событий и расстановку сил в своей жизни» [1, с. 285]. М. А. Щукина видит в личностной зрелости этап личностного развития, «этап не предзаданный и не гарантированный личности в результате ее взросления и социализации» [16, с. 316]. В этом случае, личностная зрелость - это результат выбора самого человека: выбор быть социально активным и автономным, управлять своим поведением и жизнью, стремиться к самоактуализации $[17,18]$. Н. Е. Харламенкова определяет личностную зрелость как способность человека к осуществлению спонтанного поведения. Спонтанное поведение она характеризует уровнем интеграции эго-идентичности и степенью интериоризации ценностей, внутренней направленностью мотивации и согласованным с нею контролем поведения [15]. Такое понимание особенно важно для нас: мы считаем, что только зрелая личность может сделать свою жизнь предметом преобразований и выступить субъектом (автором) собственной жизни.

Способность быть субъектом (автором) своего развития - родовая способность человека. В то же время, в реальной жизни человек проявляет большую (при саморазвитии) или меньшую (при развитии) меру субъектности 
по отношению к своим преобразованиям. Н. А. Логинова называет эту особенность интраиндивидуальной вариативностью субъектности развития: уровень субъектности может меняться в зависимости от ситуации, от того, считает ли человек ситуацию значимой настолько, чтобы включить все ресурсы для принятия жизненного решения [12]. Д. А. Леонтьев описывает неоднородность полноты проявления человеческой сущности в разных жизненных ситуациях, используя понятие «пунктирный человек»: «Имея возможность функционировать на разных уровнях, человек предпочитает не тот уровень, который свойственен ему в его высших человеческих проявлениях, а более низкие, субчеловеческие уровни. Сущность человека заключена в возможности переключаться с одного уровня на другой, двигаться по траектории, включающей отрезки движения на разных уровнях» [9]. Мы согласны с К. А. Абульхановой-Славской, что в некоторых ситуациях возможно преобладание двух типов жизненной стратегии личности: человек может начать выстраивать себя в соответствии с выбранными целями еще в дошкольном возрасте, а может никогда не стать субъектом своего развития: «осознавая свой идеал, его отличие от реального Я, многие люди не стремятся себя изменить» [1, с. 261].

В работе Е. Л. Солдатовой и И. А. Шляпниковой личностная зрелость - это качество, позволяющее человеку наиболее полно и эффективно реализовать себя в мире (обществе). Авторы утверждают, что компоненты личностной зрелости состоят их двух групп переменных: 1) компоненты личности, которые указывают на ее сформированность/зрелость (Я-концепция, система ценностей и личностных смыслов и т. д.), и 2) обобщенные свойства личности, которые являются способами самовыражения и самоосуществления личности - автономия, независимость, ответственность, активность и т. п. [14, с. 68]. В настоящем исследовании попытаемся описать компоненты личностной зрелости: сформированная эго-идентичность, активное владение собственным окружением (Е. И. Головаха), самореализация как личностный смысл и авторство собственной жизни.

Мы считаем, что закладка компонентов личностной зрелости происходит в возрасте 7-8-ми лет [3]. Поступая в школу, ребенок входит в новую социальную роль: изменяется социальная ситуация развития, изменяются его отношения с родителями и сверстниками [4]; расширяются представления о мире, происходит осознание границ своего Я, исследование своих возможностей. Полагаем, что представления о себе (эго-идентичность) и о своем месте в мире/обществе (активное владение собственным окружением) формируются в своей основе в данный период.

Для проверки нашего предположения было проведено лонгитюдное исследование. 


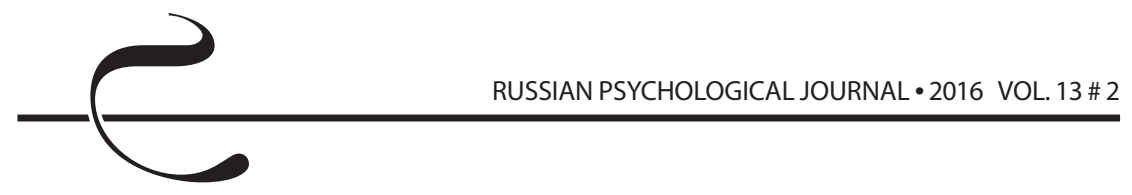

В группу лонгитюда, тестируемую на протяжении 18 лет, изначально вошли 232 ученика 1-х классов общеобразовательных школ №№ 35, 63, 90, 125, 152 г. Самары и г. Тольятти, в возрасте 7-8 лет. Из них приняли участие во всех срезах логнитюда 96 человек. Первое исследование было проведено, когда испытуемые обучались в 1-м классе (1997-1998 гг.). К моменту последнего исследования (2014-2015 гг.) все испытуемые успешно закончили школьное обучение и получили среднее специальное и/или высшее образование (средний возраст - 24-25 лет).

Для исследования проявлений компонентов личностной зрелости были использованы следующие методы: сочинение на тему «Я человек», методика предельных смыслов Д. А. Леонтьева, а также контент-анализ и метод экспертных оценок.

\section{Процедура исследования}

На первом этапе (1997-1998 гг.) испытуемые писали сочинение на тему «Я человек». Два понятия - индивидуализированное «Я» и родовое «Человек», вынесенные в заголовок сочинения, позволяют автору текста определить собственное место в мире (обществе). На наш взгляд, континуум понятий «Я» - «Человек» охватывает большой пласт представлений о себе за счет актуализации потенциального сознания. Представления о себе и своем месте в мире (обществе) могут указывать на особенности презентации образа эго-идентичности, его эмоциональную окраску (личностный смысл).

На втором этапе исследования (2014-2015 гг.) испытуемых просили написать сочинение «Я человек», также с ними проводилась методика предельных смыслов Д. А. Леонтьева [8]. Использование последней методики позволяет рассматривать личность как психологическое образование и как регуляторную систему, которая конституируется тремя функциями. Это: 1) выделение своего Я из окружающего мира, 2) самопрезентация и структурирование своих отношений с миром (обществом), и 3) подчинение своей жизнедеятельности устойчивой структуре этих отношений. Перечисленные функции осуществляет главная, конституирующая подструктура личности - ее смысловая сфера. Здесь смысловая сфера личности предстает как организованная совокупность смысловых образований (структур) и связей между ними, которая обеспечивает смысловую регуляцию жизнедеятельности человека во всех ее аспектах [9, с. 154].

В качестве основного метода анализа данных был выбран качественный, поскольку он позволяет проводить индивидуальный и сравнительный анализ результатов путем выявления их содержательного контекста. Тенденции проявления компонентов личностной зрелости, полученные при совмещении контент-анализа материалов сочинения и экспертной оценки, можно считать 
вполне легитимными для реальных условий, недоступных для исследования другими методами.

\section{Результаты}

В процессе контент-анализа определились четыре типа текстов сочинений «Я человек»: 1) «Я», 2) «Человек», 3) «Я и человек», 4) «Я - человек». Отметим, что «Герой» - главный действующий персонаж - является одной из существенных характеристик текстов сочинений, он отражает позицию автора и может выявить некоторые аспекты компонентов личностной зрелости (активное овладение собственным окружением и самореализация) и обнаружить результат самоопределения в рамках «индивидуальное - социальное» (эго-идентичность).

Тексты сочинений с Героем «Я» написаны о себе как об отдельно взятом индивиде. Испытуемые перечисляли свои личные свойства и предпочтения, размышляли о себе вне мира (общества). В текстах отсутствуют переживания по поводу своего статуса и отношений к себе, оценке Я другими людьми. Подобная сосредоточенность на собственных ощущениях и переживаниях, фиксация на мыслях, представлениях и состояниях свидетельствуют о Я-центрированности. Тексты с Героем «Я» могут рассматриваться как одни из самых ранних проявлений компонентов личностной зрелости, когда собственное Я уже осознанно (эго-идентичность), но интериоризация ценностей еще не завершена. Такие результаты, демонстрируемые на первом этапе лонгитюда, отражают закономерный этап в развитии личности (по Б. С. Братусю, низший уровень личностно-смысловой сферы личности - эгоцентрический [2]), тогда как для испытуемых 24-25-ти лет подобная Я-центрированность, сосредоточенность на собственных мыслях и состояниях может указывать на эгоцентризм и даже на личностный и социальный инфантилизм.

Тексты сочинений с Героем «Человек» написаны об обобщенном человеке, свойства и характеристики которого не связаны и не соотнесены с личным Я испытуемого. Такая позиция может говорить об отсутствии автономизации личности от других людей и низкой способности владеть собственным окружением. М. Кун и Т. Макпартлэнд [6] отмечают, что для субъективного благополучия человека в его Я-концепции должны быть представлены социальные роли и индивидуально-личностные характеристики. Неудивительно, что концентрация на «Человеке» не позволяет проявиться компонентам личностной зрелости: испытуемый словно «прячется» за обобщенными представлениями о должном, рисуя образ человека-функционера.

Тексты сочинений с Героем «Я и Человек» состоят из двух последовательных частей: героем одной части является «Я», героем второй - «Человек». 
С одной стороны, испытуемый выделяет себя из мира (общества) - Я, с другой стороны, он осознает существование человеческого рода, знает о предназначении человека. Надо сказать, что представления о ролях и позициях, возможность «примерить» их на себя позволяют «расшатать» Я-центрированность человека, способствуют развитию координации его действий и отношений с другими людьми, т. е. формируют способность к децентрации (в противовес эгоцентризму). Полагаем, что такие сочинения можно отнести к переходному типу, отражающему процесс становления личностной зрелости: движение от Я к социальной общности, к «Я - человек».

Тексты сочинений с Героем «Я - Человек» написаны о себе как о представителе человеческого рода. Испытуемые соотносили личные характеристики со свойственными человеку как таковому, рассматривали других людей равными себе («тоже человек», «как и я»). Подобная включенность/встроенность испытуемых в культуру, умение согласовывать нормы окружающей среды с личностными ценностями отражает способность человека реализовывать отношение «общего - особенного - уникального» на всех уровнях психологической реальности (Г. А. Цукерман). В этом случае целесообразно отметить, что: а) для осмысленного отношения к другим людям у испытуемых должна быть сформирована эго-идентичность, б) для развития личностной (в узком значении - социальной) зрелости испытуемому необходимо интериоризировать ценности культуры, общества. В целом, данный тип сочинений может указывать на высокий уровень проявлений личностной зрелости.

В таблице 1 представлены четыре типа текстов сочинений «Я человек»: 1) «Я», 2) «Человек», 3) «Я и Человек», 4) «Я - Человек» по результатам первого и второго этапа исследований.

Таблица 1.

\section{Герои сочинений на первом и втором этапах лонгитюдного исследования (в \% к общему числу сочинений)}

\begin{tabular}{|c|c|c|c|c|}
\hline $\begin{array}{c}\text { Герой } \\
\text { сочинения }\end{array}$ & Я & Человек & Я и Человек & Я - Человек \\
\hline 1997 г. (1 класс) & 69,6 & 9,8 & 8,0 & 11,6 \\
\hline 2015 г. (25 лет) & 23,1 & 23,1 & 15,4 & 38,5 \\
\hline
\end{tabular}

Мы видим, что на первом этапе исследования преобладают тексты сочинений с Героем «Я» (69,6 \%); на втором этапе лонгитюдного исследования количество таких сочинений уменьшается почти втрое $(23,1 \%)$. Тексты сочинений с Героем «Человек» и «Я и Человек» на первом этапе исследования занимают второе место (9,8 \% и 8 \%), ко второму этапу исследования их количество увеличивается незначительно и становится равным текстам 
с Героем «Я» $(23,1 \%$ и 15,4 \%). Тексты сочинений с Героем «Я - Человек» на первом этапе исследования оказались самыми малочисленными (11,6 \%). На втором этапе исследования количество данных текстов увеличилось почти в четыре раза и стало преобладающим (38,5 \%).

Таким образом, процесс становления личностной зрелости начинается с осознания себя («Я»); затем появляется образ человека - носителя социальных ролей («Человек», «Я и Человек»), человека - современника эпохи, который умеет функционировать в обществе и соответствовать нормам и правилам культуры (чем больше он овладевает культурой, «встраивается» в общество, тем выше уровень развития его социальной зрелости. А. А. Гудзовская). Далее возможен переход к самореализации («Я - Человек»): человек понимает, что он есть в мире/обществе и осознает свою включенность в культуру, человек создает условия для своего развития [см. 10], воздействует на себя и других людей через различные формы внешней и внутренней активности и выступает автором внутреннего мира.

Для оценки смысловой регуляции жизнедеятельности личности была использована методика предельных смыслов Д. А. Леонтьева. Ряд интересных результатов был получен благодаря идее В. Ю. Котлякова [5] о том, что большинство личностных смыслов можно объединить в более крупные категории. В итоге все смыслы были сведены к шести группам: альтруистические, экзистенциальные, гедонистические, статусные, коммуникативные, семейные, когнитивные и самореализация (см. таблицу 2).

Таблица 2.

Основные категории личностных смыслов (по В. Ю. Котлякову)

\begin{tabular}{|c|c|}
\hline $\begin{array}{c}\text { Личностные смыслы (категории } \\
\text { по В. Ю. Котлякову) }\end{array}$ & Сумма ранговых значений (среднее)* \\
\hline Альтруистические & 15,36 \\
\hline Экзистенциальные & 11,29 \\
\hline Гедонистические & 11,89 \\
\hline Статусные & 15,25 \\
\hline Коммуникативные & 12,82 \\
\hline Семейные & 12,54 \\
\hline Когнитивные & 16,18 \\
\hline Самореализация & 10 \\
\hline
\end{tabular}

* чем меньше сумма ранговых значений, тем больший вес имеет категория в системе жизненных смыслов (и наоборот).

По данным методики предельных смыслов обнаружились ведущие категории смысловой сферы - «Самореализация» (10) и «Экзистенциальные» смыслы $(11,29)$. Похоже, что такие результаты могут быть связаны с возрастными 


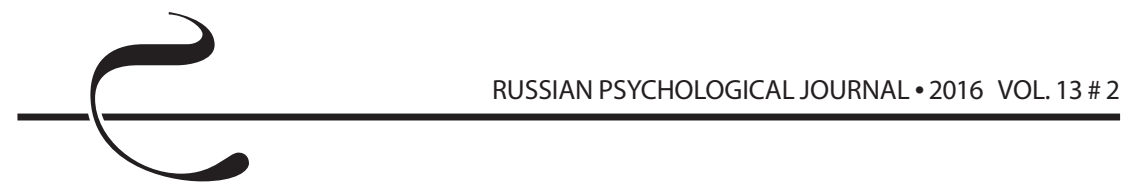

особенностями испытуемых: в 24-25 лет человек пребывает на завершающей стадии формирования собственной структуры ценностей и впервые испытывает подлинное авторство в реализации собственного взгляда на жизнь (см. В. В. Шпунтова, 2008). На данном этапе конструируются цели на ближайшие годы, остро ставится вопрос о предназначении и поиске своего места в мире (обществе).

Анализируя категории личностных смыслов испытуемых в зависимости от типов текстов сочинений «я человек», мы выявили следующее:

- у испытуемых с Героем «Я» значимой категорией выступили экзистенциальные смыслы, незначимой - группа смыслов «Статус»;

- у испытуемых с Героем «Человек» и «Я и Человек» значимой категорией оказались гедонистические смыслы и «Статус», незначимыми - когнитивные смыслы;

- среди ведущих категорий смысловой сферы испытуемых с Героем «Я Человек» значимой оказалась «Самореализация», незначимыми - «Альтруизм» и когнитивные смыслы (см. таблицу 3).

Таблица 3.

Основные категории личностных смыслов в зависимости от типов текстов сочинений «Я человек»

\begin{tabular}{|c|c|c|c|c|c|c|c|c|}
\hline & \multicolumn{8}{|c|}{$\begin{array}{c}\text { Основные категории личностных смыслов (ранговые } \\
\text { значения*) }\end{array}$} \\
\hline $\begin{array}{l}\text { Герой } \\
\text { сочинения }\end{array}$ & 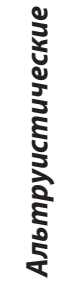 & 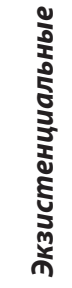 & 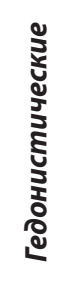 & 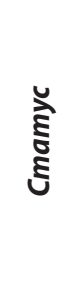 & 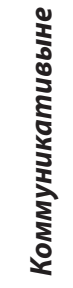 & 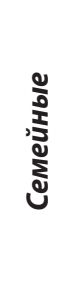 & 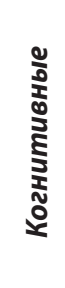 & 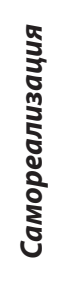 \\
\hline Я & 16 & 6,3 & 7,7 & 16,3 & 9 & 9 & 14,3 & 8,3 \\
\hline Человек & 16,8 & 14 & 11,5 & 13,5 & 13,5 & 13,3 & 15,3 & 8,3 \\
\hline Я и Человек & 20 & 13 & 8 & 8,5 & 15 & 11 & 22,5 & 9 \\
\hline Я - Человек & 13,2 & 10,9 & 11,4 & 14,4 & 11,3 & 11,6 & 14,6 & 8,9 \\
\hline
\end{tabular}

* чем меньше сумма ранговых значений, тем больший вес имеет категория в системе жизненных смыслов (и наоборот).

Прокомментируем результаты. При выраженной позиции Я значимыми категориями личностных смыслов являются экзистенциальные $(6,3)$, гедонистические смыслы $(7,7)$ и «Самореализация». Центрируясь на себе 
и собственных ощущениях, человек отделяет себя от окружающего мира. Возможно, он строит траекторию жизненного пути, сосредотачивается на временной перспективе и долгосрочном планировании (преобладание экзистенциальных смыслов), или же растворяется в каждодневных рутинных действиях и акцентируется на чувственных удовольствиях (преобладание гедонистических смыслов). В качестве иллюстрации, позволяющей обрисовать второй способ существования, обратимся к А. В. Серому: «Эгоцентризм проявляется в замкнутости в своем мире, настороженности по отношению к людям и сухости в контактах с ними... склонность к раздумьям и инертность в принятии решений, как правило, выражаются в податливости характера и декларируемой конвенциональности. Данное состояние характеризует человека как гедониста, живущего сегодняшним днем и не имеющего целей» [13, с. 105-107].

При выраженных позициях «Человек» и «Я и Человек» значимыми категориями личностных смыслов являются «Гедонистические» (8) и «Статусные» $(8,5)$. В поисках социальной идентичности человек стремится самоопределиться и утвердить свою автономность, он формирует принадлежность к нормам и ценностям группы на уровне самосознания и реального поведения [см. 4]. При доминировании гедонистических смыслов человек прагматичен и ориентирован на материальное благополучие и обеспеченную жизнь, он жаждет удовольствий, которые можно разделить с семьей и друзьями. Его ориентиры - наличие ситуативных целей, витальная направленность жизненного самоопределения и отсутствие общего смысла жизни. Вторая ситуация - выраженность статусных смыслов - может указывать на желание испытуемых добиваться успеха, строить карьеру и продолжать искать достойное положение в обществе. Согласно изложенным представлениям, процесс поиска эго-идентичности является важным этапом на пути становления личностной зрелости. Зная особенности жизненного пути, человек может выбрать оптимальный вариант собственного развития, определить жизненный путь [11]. В целом, активность личности имеет определенные ограничения $[10,19,20]$. В объективном плане свобода личности ограничена социально-историческими условиями, в субъективном плане - выбором и позицией личности по отношению к своей жизни.

Если преобладает позиция «Я - Человек», то наиболее значимой категорией личностных смыслов выступает «Самореализация» $(8,3$ и 8,9). Перенимая нормы общества, человек соотносит себя с другими людьми; он идентифицируется с референтной группой и адаптируется к миру/обществу. Удовлетворение потребности принадлежности группе - одной из базовых потребностей человека (А. Маслоу) - способствует: а) становлению адекватной, устойчивой и внутренне непротиворечивой эго-идентичности, 


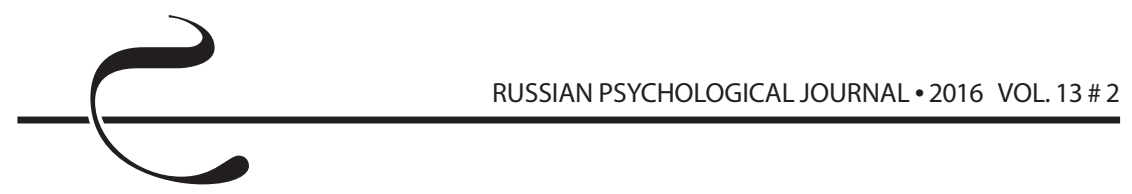

б) получению положительной обратной связи, построенной на сопричастности к ценностям и нормам культуры, в) выстраиванию жизненной перспективы и формулированию целей жизни, которые являются значимыми компонентами личностного смысла.

\section{Выводы}

Становление личностной зрелости происходит в процессе решения человеком жизненных задач и построения отношений с миром (обществом). По сути, человек может достичь зрелого возраста с течением времени, однако для того, чтобы стать зрелой личностью, ему необходима сознательная работа над собой. Еще раз подчеркнем, что достижение личностной зрелости - есть процесс и результат развития человека в заданном социокультурном пространстве на определенном этапе жизненного пути. Личностная зрелость указывает на то, что поведение человека активно, а не реактивно, что человек является хозяином обстоятельств и автором (творцом) своей жизни.

Компонентами личностной зрелости являются: сформированная эго-идентичность, активное владение собственным окружением - способность вести себя независимо от воздействующих обстоятельств и руководствоваться собственными, сознательно поставленными целями, самореализация. В своей основе они формируются в 7-8 лет: в данном возрасте закладывается процесс целенаправленного и организованного овладения целостными, устойчивыми чертами и качествами, необходимыми для успешной жизнедеятельности; в последующие возрастные периоды происходит развитие личностной зрелости за счет «разворачивания» ее компонентов.

\section{Литература}

1. Абульханова-Славская К. А. Стратегия жизни. - М.: Мысль, 1991. - 299 с.

2. Братусь Б. С. Аномалии личности. - М.: Мысль, 1988. - 301 с.

3. Гудзовская А. А. Психология социальной зрелости: монография. Самара: Изд-во СИПКРО, 2014. - 256 с. - URL: http:// elibrary.ru/item. asp?id=237386342014

4. Кон И.С. В поисках себя: Личность и ее самосознание. - М.: Политиздат, 1984. - 335 C.

5. Котляков В. Ю. Методика исследования системы жизненных смыслов // Сибирская психология сегодня: Сборник научных трудов». Вып. 2. Кемерово: Кузбассвузиздат, 2003. - С. 18-21.

6. Кун М., Макпартлэнд Т. Эмпирическое исследование установок личности на себя // Современная зарубежная социальная психология: тексты / Под ред. Г. М. Андреевой, Н. Н. Богомоловой, Л. А. Петровской. - М.: Изд-во Моск. ун-та, 1984. - С. 180-187. 
7. Леонтьев А. Н. Лекции по общей психологии. - М.: Смысл, 2001. - 511 с.

8. Леонтьев Д. А. Методика предельных смыслов (МПС). - М.: Смысл, 1992. - 36 с.

9. Леонтьев Д. А. Психология смысла: природа, строение и динамика смысловой реальности. - М.: Смысл, 2003. - 487 с.

10. Леонтьев Д. А. Самореализация и сущностные силы человека // Психология с человеческим лицом: гуманистическая перспектива постсоветской психологии / Под ред. Д. А. Леонтьева, В. Г. Щур. - М., 1997. - С. 156-175.

11. Логинова Н. А. Жизненный путь человека как проблема психологии // Вопросы психологии. - 1985. - № 1. - С. 103-109.

12. Логинова Н. А. Психобиографический метод исследования и коррекции личности: Учебное пособие. - Алматы: Казак университеті, 2001. - 176 с.

13. Серый А. В. Система личностных смыслов: структура, функции, динамика. - Кемерово: Кузбассвузиздат, 2004. - 272 с.

14. Солдатова Е. Л., Шляпникова И. А. Эго-идентичность как системообразующий фактор формирования личностной зрелости // Вестник Южно-Уральского государственного университета. Серия: Психология. 2010. - № 27 (203). - С. 66-74.

15. Харламенкова Н. Е. Спонтанность и контроль в зрелых личностных отношениях // Феномен и категория зрелости в психологии / Отв. ред. А. Л. Журавлев, Е. А. Сергиенко. - М.: Изд-во ИП РАН, 2007. - С. 128-148.

16. Щукина М. А. Психология саморазвития личности: субъектный подход: дисс. ... д-ра психол. наук. - СПб., 2015. - 355 с.

17. Щукина М. А. Субъектный подход к саморазвитию личности: возможности теоретического понимания и эмпирического изучения // Психология. Журнал Высшей школы экономики. - 2014. - № 2. - С. 7-22.

18. Maslow A. Religions, Values, and Peak-Experiences. - N. Y.: Viking press, 1970. - 123 p.

19. Rokeach M. Beliefs, Attitudes, and Values. - San Francisco: Jossey-Bass, 1969. - $214 \mathrm{p}$.

20. Royce J. R., Powell A. Theory of personality and individual differences: factors, systems and processes. - Englewood Cliffs (N. J.): Prentice-Hall, 1983. - 304 p. 